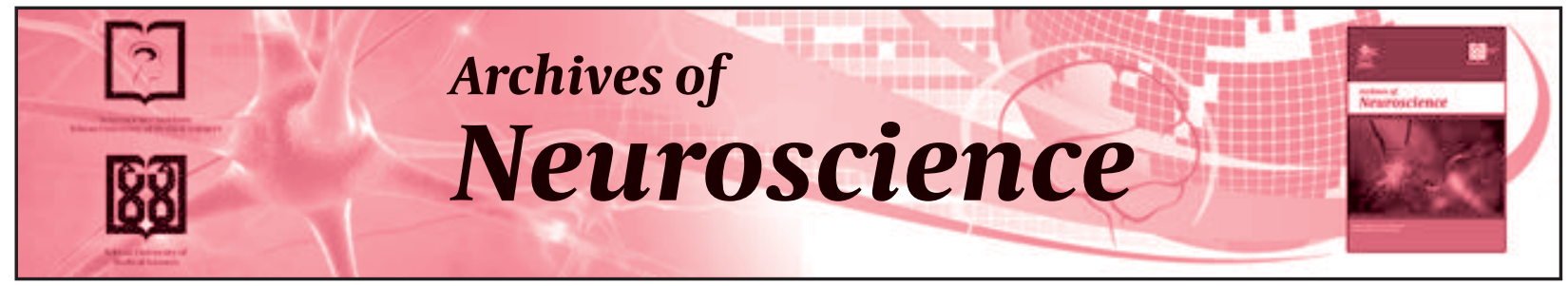

\title{
Evaluation of Mood Effects Due to Chronic Exposure to Solvents in a Tire Factory
}

\author{
Omid Aminian ${ }^{1}$, Samineh Hashemi ${ }^{2,}$, Aidin Shariatzadeh ${ }^{2}$ \\ ${ }^{1}$ Department of Occupational Medicine, Faculty of Medicine, Tehran University of Medical Sciences, Tehran, Iran \\ ${ }^{2}$ Center for Research on Occupational Disease, Tehran University of Medical Sciences, Tehran, Iran \\ *Corresponding author: Samineh Hashemi, Center for Research on Occupational Disease, Tehran University of Medical Sciences, Tehran, Iran. Tel: +98- \\ 9123303056, Fax:+98-2188013281, E-mail: brakialis@yahoo.com.
}

\begin{abstract}
A B S T R A C T
Background: Exposure to solvents is a common event in industrial factories, and has numerous acute and chronic neuro-behavioral effects on workers.

Objective: In this study, we tried to evaluate the effects of long time exposure to solvents on the mood alteration of workers in a tire factory. Patients and Methods: In this cross sectional study, we selected 90 men who were exposed to solvents in a tire factory and compared their behavior-mood test (POMS) with 70 people in a control group who had no exposure to solvents. This questionnaire consisted of 64 words that described the individual's emotions. Each person selected one of the five levels for stating emotions (from $0=$ never to $4=$ very much). $\mathrm{A}$ positive score from 0 to 4 belonged to each item, and the total score was the sum of all scores. First, demographic information was collected in a questionnaire. Then, we used another questionnaire with 16 questions for detecting neuro-behavioral disorders due to continuous exposure to solvents in both groups.

Results: There was no statistically significant difference between the two groups based on age and educational level $(\mathrm{P}>0.05)$. The mean of employment duration in the exposed group was significantly longer than the control group $(\mathrm{P}<0.05)$. The results of comparing the two groups in six mood levels showed no statistically significant difference $(\mathrm{P}>0.05)$.

Conclusion: According to our results, the Q16 questionnaire is recommended as a screening tool in periodic examinations of workers exposed to solvents. Questionnaire evaluations are used to help determine whether long-term overexposure to solvents has affected the central nervous system (brain).
\end{abstract}

Keywords: Rubbers Solvent; Affect; Occupational Exposures

Copyright @ Tehran University of Medical Sciences; Published by Kowsar Corp.

Article type: Research Article; Received: 26 Jan 2013; Revised: 24 Apr 2013; Accepted: 29 Apr 2013; Epub: 01 Apr 2014; Ppub: 20 Apr 2014

-Implication for health policy/practice/research/medical education:

The Q16 questionnaire is recommended as a screening tool in periodic examinations of workers exposed to solvents. Questionnaire evaluations are recommended for workers with a long history of exposure to solvents.

-Please cite this paper as:

Aminian O, Hashemi S, Shariatzadeh A. Evaluation of Mood Effects Due to Chronic Exposure to Solvents in a Tire Factory. Arch Neuro Sci. 2014; 1(1):31-4. DOI: 10.5812/archneurosci.10424

Copyright @ Tehran University of Medical Sciences; Published by Kowsar Corp.

This is an Open Access article distributed under the terms of the Creative Commons Attribution License (http://creativecommons.org/licenses/by/3.0), which permits unrestricted use, distribution, and reproduction in any medium, provided the original work is properly cited. 


\section{Background}

Solvents have various applications in industry $(1,2)$. In 1974, The American National Institute for Occupational Safety and Health (NIOSH) estimated that approximately 9.8 millions workers had been exposed to solvents (3). Therefore, exposure to solvents is a common event, and is considered as one of the important occupational exposures (4). Exposure to solvents has various acute and chronic effects on biological systems $(5,6)$. Since solvents are accumulated in fat-rich tissues, the nervous system is very vulnerable to toxic effects of solvents. Chronic exposure to solvents may result in memory and concentration disturbance, mood alteration, libido reduction and fatigue. There are mixed results about neuro-behavioral effects and mood alterations due to chronic exposure to solvents (7). Some investigations have found a significant association between mood disturbance and chronic exposure to solvents $(8,9)$; whereas, some other studies have proven no association $(10,11)$. In 2011 , a study was designed for evaluation of neuro-behavioral effects of occupational exposure to ethyl benzene. The study did not find a significant difference between four mood levels and the control group (12).

Diagnosing personality and cognitive alterations of people is necessary for physicians, so various tests have been provided for evaluating neuro-behavioral function. One of these tests, which is also recommended by the World Health Organization (WHO), includes seven different tests for evaluating short term memory, reaction time, concentration and mood (13). These tests are conducted among participants whose occupation involves exposure to metal, pesticides, and solvents which can damage the central nervous system $(14,15)$.

\section{Objectives}

In this study, we evaluated the effects of long time exposure to solvents on the mood alteration of workers in a tire factory. Since in many cases these effects do not have overt clinical manifestations, early recognition of patients with the tests may be helpful for preventing non reversible complications.

\section{Patients and Methods}

In this cross sectional study, we selected 90 men who were exposed to solvents in a tire factory and compared their behavior-mood test (POMS) with 70 people in a control group. Control group included individuals who were working in the administrative section of the same factory with no history of exposure to solvents.

We first identified areas of the factory with high level of exposure to solvent. First, certain regions of the factory with high exposure to solvent were identified. In the samples provided from the air of tire and tube heating saloons, the rate of exposure to some solvents such as benzene, petrol and toluene tested higher than permit- ted levels. Therefore, we selected 100 male workers with a minimum 8 hour working day and at least a 3 year history of working in tire and tube heating saloons. Among them, 10 workers were excluded because of meeting at least one of the following exclusion criteria: history of head trauma, seizure and drug consumption, education of less than 8 years, alcohol consumption during the last 24 hours, and inadequate sleeping during the previous night. The group without exposure included 82 employees. Twelve of these employees were excluded because of the aforementioned criteria. Demographic information such as age, employment history, and educational level, medical and occupational history was collected by a questionnaire. A questionnaire with 16 questions (the q16 questionnaire) was used to detect neuro-behavioral disorders in workers. This questionnaire has been used in other studies as a primary and sensitive screening tool for detecting neuro-behavioral disorders due to continuous exposure to solvents $(3,7)$, and is based on the clinical experiments of workers who have been exposed to solvents for years.

Questionnaires were completed after adequate explanation and obtaining consent from workers. If participants had positive answers to six or more questions, more clinical evaluations were recommended. However, this questionnaire is not used alone to prove complications due to solvents (16).

For mood evaluations we used another questionnaire recommended by the World Health Organization. This questionnaire consisted of 64 words that describe individual's emotions, and each person had to choose one of the five levels for stating emotions (from $0=$ never to 4 = very much). Participants had to complete the questionnaire within 5 minutes. They were constructed to demonstrate their emotional conditionings during the last week. This consisted of both constant mood conditions and short time feelings which had developed recently.

According to the protocol of The American National Institute for Occupational Safety and Health (NIOSH), we used activated carbon for determining the concentration of solvents in the air of factory. Then, results were analyzed by gas chromatography analyzer apparatus (Table 1). In addition, the index of exposure to the mixture of solvents was acquired via the summation of the ratio of gas concentration / permitted threshold.

Finally, the data was analyzed by SPSS software ver-18, and chi-2 and t-test were used for comparing the two groups.

\section{Results}

Demographic information has been summarized in $\mathrm{Ta}$ ble 2. According to Table 2, there is no statistically significant difference between the two groups based on age and educational level $(\mathrm{P}>0.05)$. However, the employment 
duration in the exposed group was significantly longer than control group $(\mathrm{P}<0.05)$.

Table 1. Solvents Concentration in the Air Samples Provided From the Tire Factory Environment

\begin{tabular}{lll}
\hline Solvent & Concentration, ppm & Permitted Threshold \\
\hline Benzene & 0.6 & 0.5 \\
Toluene & 6.007 & 50 \\
Petrol & 182.7 & 300 \\
\hline
\end{tabular}

Comparing theresponses to the16-questionsquestionnaire indicated a statistically significant difference between the two groups for the ratio of people who gave positive answers to at least six questions $(\mathrm{P}<0.05)$. In the exposed group, 12 cases (12.6\%) responded positively to at least six questions, and the rest (87.4\%) had positive answers to less than six questions; whereas, in the nonexposed group, all of the cases had positive answers to less than six questions. The results of comparing the two groups in six mood levels are shown in Table 3. According to this table, there is no statistically significant difference between these two groups $(\mathrm{P}>0.05)$.

Table 2. Demographic Information of the GroupWith Exposure to Solvents and the Group Without Exposure to Solvents

\begin{tabular}{llll}
\hline Variables & $\begin{array}{l}\text { Without Expo- } \\
\text { Sure, No.(\%) }\end{array}$ & $\begin{array}{l}\text { With Expo- } \\
\text { sure, No.(\%) }\end{array}$ & P-value \\
\hline $\begin{array}{l}\text { Total } \\
\text { population }\end{array}$ & 82 & 100 & \\
$\begin{array}{l}\text { Participated } \\
\text { population }\end{array}$ & 70 & 90 & \\
$\begin{array}{l}\text { Age, mean } \\
\text { (SD) }\end{array}$ & $28.7(6.1)$ & $28.2(3.7)$ & 0.555 \\
$\begin{array}{l}\text { Education }< \\
\text { Diploma }\end{array}$ & $13(16.5 \%)$ & $26(27.4)$ & 0.086 \\
$\begin{array}{l}\text { Education }> \\
\text { Diploma }\end{array}$ & $66(83.5 \%)$ & $69(72.6)$ & \\
$\begin{array}{l}\text { Employment } \\
\text { history, } y\end{array}$ & $4.3(4.1)$ & $5.8(2.7)$ & 0.004 \\
\hline \begin{tabular}{l} 
Smoking \\
\hline
\end{tabular} & $19(24)$ & $28(29.5)$ & 0.422 \\
\hline
\end{tabular}

\section{Discussion}

In our study, there was no significant difference in age and education between the two groups, but the duration of employment was greater in the exposed group and this difference was statistically significant. Regarding the Q16 questionnaire the prevalence of people who had positive answers to more than six questions was higher in the exposed group. This questionnaire has been introduced as a screening tool for detecting disorders due to long term exposure to solvents.
According to designers` recommendations, cases with positive results should be clinically examined by a physician and after confirmation by the physician, it must be confirmed by clinical examination and appropriate psychological and neuro-physiological tests. However, because of some limitations, performing all of these stages were not possible (16).

In our study, regarding comparing moods in the two groups (POMS), a mean of 5 negative moods were higher in the exposed group but this difference was not statistically significant. In addition, regarding positive moods, the mean was higher than the nonexposed group, but the difference was not significant. This finding is similar to others performed by investigations (10-12), but differs from other studies $(17,18)$. Based on our findings and similar studies (19) in which the mean of the history of working duration is six years, more time may be necessary for developing mood alterations. In addition, applying the Persian version of the WHO questionnaire may be effective in acquired results.

Table 3. Results of Mood Evaluation in Exposed and Nonexposed Solvent Groups

\begin{tabular}{llll}
\hline Indicator & $\begin{array}{l}\text { Nonexposed, } \\
\text { mean } \pm \text { SD }\end{array}$ & $\begin{array}{l}\text { Exposed, } \\
\text { mean } \pm \text { SD }\end{array}$ & P-value \\
\hline $\begin{array}{l}\text { Tension- } \\
\text { anxiety }\end{array}$ & $5.1 \pm 6.7$ & $5.9 \pm 6.8$ & 0.402 \\
$\begin{array}{l}\text { Depression- } \\
\text { dejection }\end{array}$ & $11.9 \pm 8$ & $12.2 \pm 6.3$ & 0.796 \\
\hline $\begin{array}{l}\text { Enmity-angry } \\
\text { Power-energy }\end{array}$ & $9.4 \pm 6.1$ & $9.4 \pm 7.3$ & 0.996 \\
\hline $\begin{array}{l}\text { Fatigue- } \\
\text { exhaustion }\end{array}$ & $5.1 \pm 3.7$ & $13.1 \pm 4.4$ & 0.894 \\
\hline $\begin{array}{l}\text { Confusion } \\
\text {-dizziness }\end{array}$ & $4.8 \pm 2.8$ & $5.7 \pm 4.2$ & 0.495 \\
\hline
\end{tabular}

\section{Conclusions}

One of our limitations was the selection bias due to healthy workers; so that, symptomatic workers may have left their job previously, and were not in our population study. Also, our study was not a double blinded one; therefore, it is probable that patients' awareness from exposure influenced the test results. According to the results acquired from this study, it is recommended that the Q16 questionnaire be used as a screening tool in periodic examinations of workers exposed to solvents. Moreover, evaluation of mood disorders with the questionnaire is recommended for the workers with a history of longer exposures to solvents. Perhaps, it is necessary to investigate the validity of the mood questionnaire in our community.

\section{Acknowledgements}

This study has been supported by Tehran University of 
Medical Sciences (TUMS). The authors wish to express their gratitude to the staff of the Occupational Medicine Department for their kind collaboration.

\section{Authors' Contribution}

We have worked all together to conduct this study; O. Aminian has worked as a designer and coordinator of research team and drafting/editing manuscript, S Hashemi worked specially in gathering data and drafting manuscript as her residential thesis, A. Shariatzadeh helped the research team by methodological consulting and manuscript editing, and helped the research team in analyzing data.

\section{Financial Disclosure}

None declared.

\section{Funding/Support}

None declared.

\section{References}

1. Final Report on Carcinogens Background Document for Formaldehyde. Rep Carcinog Backgr Doc. 2010(10-5981):i-512

2. Final Report on Carcinogens Background Document for Styrene. Rep Carcinog Backgr Doc. 2008( 8-5978):i-398

3. Textbook of Clinical Occupational and Enviornmental Medicine. 2005.

4. Jin CF, Haut M, Ducatman A. Industrial solvents and psychological effects. Clin Occup Environ Med. 2004;4(4):597-620

5. Triebig G, Schaller KH, Weltle D. Neurotoxicity of solvent mixtures in spray painters. I. Study design, workplace exposure, and questionnaire. Int Arch Occup Environ Health. 1992;64(5):353-9

6. Ekberg K, Barregard L, Hagberg S, Sallsten G. Chronic and acute effects of solvents on central nervous system functions in floorlayers. Br J Ind Med.1986;43(2):101-6

7. Current Occupational \&Environmental Medicine. In: LaDou J, editor.McGraw-Hill; 2007.

8. Escalona E, Yanes L, Feo O, Maizlish N. Neurobehavioral evaluation of Venezuelan workers exposed to organic solvent mixtures. Am J Ind Med.1995;27(1):15-27

9. Morrow LA, Ryan CM, Goldstein G, Hodgson MJ. A distinct pattern of personality disturbance following exposure to mixtures of organic solvents. J Occup Med.1989;31(9):743-6

10. Reinvang I, Borchgrevink HM, Aaserud O, Lie V, Malt UF, Nakstad P, et al. Neuropsychological findings in a non-clinical sample of workers exposed to solvents. J Neurol Neurosurg Psych. 1994;57(5):614-6

11. Hooisma J, Hanninen H, Emmen HH, Kulig BM. Behavioral effects of exposure to organic solvents in Dutch painters. Neurotox Tera tol.1993;15(6):397-406

12. Zhang M, Wang YR, Yang DY, Wang Q, Liu J, Li JG. [The neurobehavioral effects of population occupationally exposed to ethyl benzene]. 2011;29(2):128-30

13. Geneva, Operational Guide for the WHO neurobehavioral core test battery. World Health Organization (WHO). 1986.

14. Niu Q, Zhang H, Li X, Li M. Benzo[a]pyrene-induced neurobehavioral function and neurotransmitter alterations in coke oven workers. Occup Env Med. 2010;67(7):444-8

15. Wang XL, Yang Y], Ding MY, Quan Z], Zhao XG, Nie J, et al. [Effect of heavy metals exposure on neurobehavioral function in welders] 2008;26(11):641-4

16. Lundberg I, Hogberg M, Michelsen H, Nise G, Hogstedt C. Evaluation of the Q16 questionnaire on neurotoxic symptoms and a review of its use. Occup Env Med.1997;54(5):343-50

17. Bowler RM, Lezak M, Booty A, Hartney C, Mergler D, Levin J, et al. Neuropsychological dysfunction, mood disturbance, and emotional status of munitions workers. Appl Neuropsych. 2001;8(2):74-90

18. Morrow LA, Ryan CM, Hodgson MJ, Robin N. Alterations in cognitive and psychological functioning after organic solvent exposure. J Occup Med.1990;32(5):444-50

19. Maizlish NA, Langolf GD, Whitehead LW, Fine LJ, Albers JW, Gold berg J, et al. Behavioural evaluation of workers exposed to mixtures of organic solvents. Br J Ind Med.1985;42(9):579-90 